\title{
Leopards and ghosts in the temple
}

\author{
Martin F. McKneally, MD, PhD
}

\begin{abstract}
"Leopards break into the temple and drink to the dregs what is in the sacrificial pitchers; this is repeated over and over again; finally it can be calendared in advance, and it becomes part of the ceremony."
\end{abstract}

—Franz Kafka

With this vivid image, bioethicist and University of Toronto Law Professor Trudo Lemmens characterized the engagement of industry in academic science. ${ }^{1}$ At a recent workshop $^{2}$ on the ethics of ghostwriting chaired by Lemmens, experienced ghostwriters described in detail how this technique is used for marketing surgical devices and pharmaceuticals. Talented writers prepare manuscripts designed to help market commercial medical products. These manuscripts are offered to prominent clinicians, who become guest authors by adding their names and reputation to the marketing plan after review and token editing. Honoraria, advisory board salaries, and research support are often used to enhance interest in these transactions. Although still prevalent, guest authorship is regarded as fraud in some jurisdictions. To deal with this problem, the Journal's policy on accepted manuscripts is to require the names of all contributors, some of whom might otherwise remain in the shadows as unacknowledged but well-paid ghosts. In response to such policies, I anticipate that there will be more transparent use of medical writers as acknowledged authors and contributors.

In this issue, the Journal publishes a valuable article about the kallikrein inhibitor ecallantide, a recombinant peptide in the same class as aprotinin. Aprotinin had been widely used to reduce surgical bleeding until marketing of the drug was suspended because of reports of treatmentrelated complications and deaths. ${ }^{3}$ The ecallantide study was stopped because the drug was also associated with unacceptable mortality. Of note, the study demonstrated a beneficial effect on postoperative blood loss in the comparison group of patients treated with tranexamic acid,

\footnotetext{
From the Department of Surgery and Joint Centre for Bioethics, University of Toronto, and Toronto General Hospital, University Health Network, Toronto, Ontario, Canada.

Disclosures: The author has nothing to disclose with regard to commercial support. Portions of this editorial have appeared in a column by the author in the University of Toronto Surgery Department newsletter.

Received for publication Aug 11, 2011; accepted for publication Sept 8, 2011; available ahead of print Oct 19, 2011.

Address for reprints: Martin F. McKneally, MD, PhD, Ravine Research and Education Centre, 77 Forest Grove Drive, Toronto, ON M2K 1Z4, Canada (E-mail: martin.mckneally@utoronto.ca).

J Thorac Cardiovasc Surg 2011;142:1339-40

$0022-5223 / \$ 36.00$

Copyright (c) 2011 by The American Association for Thoracic Surgery

doi:10.1016/j.jtcvs.2011.09.045
}

a fibrinolysis inhibitor made by Pharmacia \& Upjohn Inc (Bridgewater, NJ).

There was understandable concern about publication because of the extent of involvement of industry in the trial itself and in the production of the manuscript. Cubist Pharmaceuticals (Lexington, Mass), the manufacturer of ecallantide, funded the study, and editorial assistance was provided by PharmaWrite, LLC (Princeton, NJ), a commercial medical communications company. In addition, the first author is a company employee and stockholder in Cubist Pharmaceuticals, and 8 of the 9 authors disclosed financial ties to the company. The data were monitored by Global Research Services (Rockville, Md), a commercial contract research organization, and analyzed by InVent Clinical (Indianapolis, Ind), another independent contract research organization. Nevertheless, 3 careful reviewers, Associate Editor John Ikonimidis, and Editor-in-Chief Lawrence Cohn were impressed by the value of the clinical contribution.

In this commentary, I explain the reasoning behind the decision to publish the article and discuss ghostwriting as a form of commercial speech. I also sketch criteria for judging and managing publications from industry.

Should the Journal publish articles so extensively linked to commercial companies? Although the intuitive initial response might be negative, analysis at the rational and reflective levels leads us to a different conclusion. Rationally, we should not exclude any class of authors categorically on the basis of their affiliation, anymore than we would exclude a manuscript from a particular hospital, university, or organization. No policy, precedent, principle, or bylaw precluded acceptance.

A reflective decision about publication should be based on values. The salient values that guide our editorial decisions are scientific merit, including freedom from bias, interest to readers, and usefulness to the profession. The ecallantide article was judged to be scientifically sound, interesting, and useful. So, what were the ethical issues that caused concern on our editorial board?

1. Commercialization of science. This is a valid concern, but prevention is inappropriate and unrealistic. Collaboration with industry has a long history and is now widespread and highly productive. Industry supports the majority of pharmaceutical research and most of the research on medical devices. When this collaboration is functioning optimally, the core values of science (eg, accuracy, authenticity, logic, and truthfulness) are not compromised by commercial interest in profit. 
2. Commercial bias in scientific trials and reports. When problems arise at the margins of data management, such as decisions about exclusions, time boundaries on sampling, and interpretation of adverse events, "the profit motive [risks] compromising standards of scientific truthfulness to a greater degree than in traditional academic science." 4 Authors and their institutions bear the principal responsibility for the integrity of their work, including its conduct and preparation for publication. Journals lack the resources to police the publication component of this vast enterprise, although reviewers and editors are advised to be alert against commercial messaging. Our reviewers are warned explicitly against "language that sounds more like a package insert or advertising copy than a description of the methods." Problematic manuscripts are referred to the Ethics Editor, as in this instance.

Safeguards imposed externally include governmentmandated registration of all clinical trials, publication of protocols, and, for some journals, obligatory access for reviewers to the full data. These measures create options to monitor, verify, and strengthen the oversight of research. The integrity of scientific publications is still largely dependent on trust in the reliability of all who contribute to the development of scientific progress. When egregious misrepresentation or fraud is discovered, the consequences are public disgrace and loss of reputation, as in the notorious cases of John Darsee ${ }^{5}$ and Hwang Woo-Suk. ${ }^{6}$ Fines and other legal sanctions ensue if there is intent to defraud and evidence of harm. Commercial firms may suffer financial consequences from reputational loss, but the financial stakes are so high with blockbuster drugs and devices that even million dollar settlements and fines are not always a sufficient deterrent.

3. Commercial editorial assistance in the preparation of the manuscript. This merits discussion, because there are more than 182 medical publication companies writing scientific articles for various clients. At the Toronto workshop on the ethics of ghostwriting, experienced ghostwriters told about the development, by the International Society of Medical Publications Professionals, of guidelines and a certifying examination aimed at establishing an aura of professionalism in this expanding field. Some critics view this as strategic marketing, but harmonizing these activities with the values of the science community could make a welcome contribution to clarity in the scientific literature. Alastair Matheson, ${ }^{4}$ a scholarly freelance consultant and writer, told us that a good medical communications team requires substantial technical and academic expertise, including scientists, statisticians, commercial analysts, publications planners, trial designers, professional writers, and journal specialists who know the stylistic and format preferences of particular journals, editors, and reviewers. It will not surprise readers to learn that professionally prepared articles have a rate of acceptance that is 4 times higher than the usual submitted manuscript.

The article on ecallantide turned out to be an exemplary model of commercially sponsored clinical science. I spoke to one of the authors who helped design the trial and learned that all authors had contributed significantly to the study and the report. Contributions from the commercial medical communications company were minor and acknowledged. The manuscript was not written by ghost authors. The trial was registered at clinicaltrials.gov, and the decision to terminate the study early was based on the recommendation of an independent data safety monitoring board. The findings are distinctly unfavorable to the manufacturer of ecallantide, and the report of a beneficial effect of tranexamic acid favors a competitor. Often, a negative study such as this might be buried by a commercial sponsor. The commendable decision to submit the study for peer review certainly earned my respect and endorsement of publication.

In addition to its scientific value, the ecallantide report illustrates the importance of attention by journals to conflict of interest, and the value of conscientious commercial participation in scientific publication. Just as we set standards for exhibitors at meetings and for advertisements in journals, our profession can provide guidance on the management of potential conflicts of interest in industrial authorship.

The question remains, will the acceptance of a commercially run study like this one become a Trojan horse, establishing a level of trust in commercial publication that will facilitate the acceptance of subsequent studies of less merit or integrity? Time and experience will answer. Like the ancient city of Troy, our scientific journals cannot remain permanently behind a defensive wall, but should be cautious, alert, and circumspect as we open the gates.

The author thanks Trudo Lemmens, Alastair Matheson, Eleanor and Miles Shore, and a cottage full of McKneallys for helpful comments that improved earlier versions of this editorial commentary.

\section{References}

1. Lemmens T. Leopards in the temple: restoring scientific integrity to the commercialized research scene. J Law Med Ethics. 2004;32:641-57.

2. The ethics of ghost authorship in biomedical research: concerns and remedies. Available at: www.law.utoronto.ca/visitors_content.asp?itempath $=5 / 5 / 0 / 0 / 0 \&$ cType $=$ NewsEvents\&specEvents $=4743$. Accessed September 28, 2011.

3. Mangano DT, Tudor IC, Dietzel C, for the Multicenter Study of Perioperative Ischemia Research Group and the Ischemia Research and Education Foundation. The risk associated with aprotinin in cardiac surgery. $N$ Engl J Med. 2006;354: 353-65.

4. Matheson AD. Corporate science and the husbandry of scientific and medical knowledge by the pharmaceutical industry. BioSocieties. 2008;3:355-82.

5. Stasik J. Examples of research misconduct. Available at: www.baruch.cuny.edu/ rio/research_misconduct_examples.htm. Accessed September 28, 2011.

6. Disgraced Korean cloning scientist indicted. New York Times. May 12, 2006. Available at: http://www.nytimes.com/2006/05/12/world/asia/12korea.html. Accessed September 28, 2011 